\title{
One line decreases the visibility of a simultaneous identical distant second line
}

\author{
DONALD L. KING, JACQUELINE F. MOSE, and NIKOLA S. NIXON \\ Howard University, Washington, D.C.
}

\begin{abstract}
A top line decreased the visibility of a simultaneous, identical, distant bottom line. This context-produced decrease in visibility (DV) occurred when the bottom line was masked by flanking lines and hence was less visible than the top line. It continued when the top line was three times as far from the bottom line. It disappeared without the mask. There was a hint of an opposing contextproduced increase in visibility (IV) when the lines were close together. The DV is not accounted for by numerous extant phenomena and theories. It means that the top line decreased the similarity in visibility between it and the bottom line, a contrast effect for visibility, rather than for a typical attribute. Contrast does not occur between two attributes that are perceptually equal. Therefore, the reason why two distant equally visible objects fail to result in a DV may be that their equal visibility precludes the occurrence of contrast. This DV-as-contrast theory is consistent with evidence that two groups (phenomenal wholes) are associated with both contrast and DVs, and thus also with evidence that one group is associated with both assimilation and IVs.
\end{abstract}

There is evidence that an apprehended group (the phenomenal whole that the Gestalt psychologists emphasized) is associated with assimilation (a context-produced increase in perceived similarity) among its parts (Fuchs, 1923/1967b, cited in Kanizsa, 1988; King, 1988a, review; Musatti, 1931, cited in Kanizsa, 1988). Color assimilation, including color spread, occurs among parts that are sensed as belonging to the same apprehended group (Fuchs, 1923/1967b; Koffka, 1935). Similar observations are common (Day \& Jory, 1980; van Tuijl, 1975; Ware, 1980), although not with an explicit reference to grouping. Objects are judged as closer together when they belong to the same group than when they do not (Coren \& Girgus, 1980; Gaylord, 1984, cited in Lockhead, 1988), implying that the same-group objects assimilate in spatial location. The Delboeuf, Ebbinghaus, parallel line, Müller-Lyer, divided line, Baldwin, and Ponzo illusions and an infrequent variation of the Zöllner illusion (Coren \& Girgus, 1978 , Figure 3.2E) all suggest assimilation in geometric attributes (Coren \& Girgus, 1978; Jordan \& Schiano, 1986; Obonai, 1954), and these attributes all seem to belong to

\footnotetext{
This research was supported by the Howard University Faculty Research Support Grant Program and the National Institute of Mental Health ADAMHA-MARC Grant T-34-MHi16580. Portions of this research were reported at the 1993 meeting of the Eastern Psychological Association in Arlington, VA and at the 1993 meeting of the Psychonomic Society in Washington, DC. The helpful conversations about this research with Howard Egeth, Joseph Psotka, and Steven Yantis are appreciated. An anonymous reviewer's comments were also helpful. J. F. Mose is now at the Department of Human Development and Psychoeducational Studies at Howard University. N. S. Nixon is now at the School of Education and Human Development at George Washington University. Please send correspondence concerning this article to D. L. King, Department of Psychology, Howard University, 525 Bryant St. NW, Washington, DC 20059 (e-mail: hpsc64A@prodigy.com).
}

a relatively strong group. In closure, a gap is falsely identified as essentially identical to nearby contour, a color-spread-like spread of contour, and closure is more likely when the entire object is apprehended as a relatively strong single group (Fuchs, 1921/1967a; Hartman, 1935, p. 110; demonstrations in Ramachandran, 1992). This group-assimilation association holds for color spread when the stimulus duration is brief (Prinzmetal \& Keysar, 1989). Another finding (see Prinzmetal, 1981) can be considered analogous, except that assimilation in spatial location occurred. In addition, the apprehension of a strong group is associated with fast "same" and slow "different" responding (King, 1988b, including review; King, Phillips, \& Mose, in press), which is relevant to assimilation, because it should be easy to respond "same" but difficult to respond "different" to briefly perceived perceptually similar attributes. Group-closure evidence also occurs with stimuli that are briefly perceived (King et al., in press; King \& Thomas, 1993).

Recent evidence suggests that an apprehended group is also associated with an increase in visibility (IV) of at least one of its parts (King, Hicks, \& Brown, 1993; King $\&$ Thomas, 1993). To determine whether an IV occurs, a complete object (context-plus-target stimulus) is divided into context and target components. A blank (empty field) is also used. An IV is indicated when overall performance on a discrimination between a contextplus-target stimulus (e.g., $\square$ ) and a context stimulus (e.g., $\sqcup$ ) is better than performance on a discrimination between a target (e.g., ${ }^{-}$) and the blank. This is because a context-plus-target stimulus and a context stimulus differ by the target, as do the target (alone) and the blank. In addition, the target-versus-blank discrimination is a detection (discrimination from background) task, as distinguished from an identification (discrimination be- 
tween objects) task, such as the one used to obtain the object superiority effect (Weisstein \& Harris, 1974). The objects that have been associated with an IV seem to be apprehended as relatively strong single groups. An example: both $\square$ and $\zeta$ are associated with an IV of their top line, whereas $r$ is not (King et al., 1993). Moreover, $\square$ is apprehended as the group of one square (not, for example, four individual lines), $\zeta$ is beginning to approximate the very strong group of the vertical line that would be produced by further rotation of its top line, and $\ulcorner$ is probably more likely to be apprehended as two groups, one a vertical line and the second a horizontal line.

There is also evidence that two apprehended groups are frequently associated with contrast between those parts that belong to different groups (King, 1988a, review; Musatti, 1931). First, a progressive decrease in the proximity of components of illusions seems to increase the extent to which they are apprehended as separate groups, in accord with the gestalt principle of proximity. This decrease eventually results in contrast as well (Coren \& Girgus, 1978; Jordan \& Schiano, 1986; Obonai, 1954). Second, narrow columns and ones that are similar in luminance tend to be apprehended as a single surface (group), whereas wide columns and ones that are dissimilar in luminance tend to look like separate objects (groups), also in accord with gestalt principles. In addition, the former columns result in color assimilation, whereas the latter columns result in color contrast (Beck, 1966; Helson \& Joy, 1962). Third, an extreme object (anchor) should produce one group, and it probably makes another object (other objects) produce a second group. An anchor also repels the judgment of the attributes of this other object (these other objects), which is contrast (Bevan \& Gaylord, 1978, review). Fourth, a temporal dissimilarity between two objects forces the apprehension of two groups. In addition, it replaces assimilation with the aftereffect type of contrast (Brigell \& Uhlarik, 1979; Jordan \& Uhlarik, 1985; R. H. Pollack, 1964; Sagara \& Oyama, 1957).

There are also indications that two groups are frequently associated with a decrease in visibility (DV) of the less visible group. One or two high-luminance (more visible) objects will decrease the visibility of a lowluminance (less visible) object, according to a detection (not identification) task in which the low-luminance object is discriminated from a dark background (Fehrer \& Smith, 1962; Schiller \& Smith, 1966). In addition, the high-luminance and low-luminance objects may function as separate groups, because they do not overlap, and because they are dissimilar in luminance (i.e., the gestalt principle of similarity may apply). A second indication is that a large (more visible) rectangle impairs the perception of a spatially separated small (less visible) rectangle, with differences in physical contrast controlled, according to an identification task and also a task in which two rectangles are discriminated from one of these rectangles (King, 1990b). In addition, when the large and small rectangles are contiguous and hence tend to be apprehended as one group, the DV evidence disappears. Metacontrast is a third indication. The temporal delay between the target and mask makes each of these objects produce its own group. This delay also produces a DV of the target (metacontrast). In addition, when the mask occurs, it should be more visible than the target, because the target has already terminated. Further, the DV (metacontrast) does not occur when the target and mask are simultaneous (or nearly so), close together, and roughly equally visible (Alpern, 1953; Growney, Weisstein, \& Cox, 1977; Kolers \& Rosner, 1960; Pulos, Raymond, \& Makous, 1980), perhaps because under these conditions the target and mask are readily apprehended as a single group. So, the more visible (more intense, larger, present) object (group) decreases the visibility of the less visible (less intense, smaller, terminated) object (group).

In conclusion, there is at least some evidence that one group is associated with both assimilation and an IV (the Igroup-assimilation-IV position) and that two groups are associated with both contrast and a DV (the 2groups-contrast-DV position). Moreover, these two positions correspond: one group relates to two groups, assimilation and contrast are opposing context-produced effects on perceived similarity, and IVs and DVs are opposing context-produced effects on visibility.

But there is a marked inconsistency with the 2groupscontrast-DV position. As far as is known, two distant objects that are also simultaneous and roughly equally visible do not result in a DV, even though each of them is apprehended as its own group (two in all). Accordingly, metacontrast research indicates that a spatially separated, essentially simultaneous, roughly equally visible target and mask do not result in a DV (Alpern, 1953; Growney et al., 1977; Kolers \& Rosner, 1960). Likewise, when two spatially separated, simultaneous, equally visible objects are discriminated from one of these objects and the objects occur in a limited number of spatial locations (which should minimize search), the two-object response tends to be faster than the one-object response (King, 1990a, 1990b), even though the reverse result should occur if one object has produced a DV of the simultaneous second object or vice versa.

But this inconsistency (i.e., the absence of a DV with two distant, simultaneous, equally visible objects [groups]) may have a resolution. Recall that a more visible object (group) decreases the visibility of a less visible object (group). Thus, the visibility of the less visible object is displaced away from the visibility of the more visible object. In other words, the more visible object decreases the similarity in visibility between it and the less visible object. Therefore, it is possible that contrast occurs for visibility, as well as for typical attributes such as color. Moreover, contrast does not occur between two attributes that are perceptually equal (e.g., color [hue] contrast does not occur between two objects that are perceived as equally red). Consequently, two distant simultaneous 
equally visible objects (groups) may fail to result in a DV, because their equal visibility precludes the occurrence of the DV type of contrast.

So, we have here both an empirical position and a theory for this position: (1) When two objects are apprehended as separate groups, the more visible object decreases the visibility of the less visible object-the relative-visibility position. (2) This DV may be an instance of contrast; that is, it may be due to the same process that is responsible for contrast-the $D V$-as-contrast theory. Finally, this theory is consistent with the 2 groups-contrast-DV position, because this position also implies that contrast and DVs are closely related.

It follows that Object 1 should decrease the visibility of a simultaneous, identical, distant Object 2 when $\mathrm{Ob}$ ject 2 is less visible than Object 1 . This situation can be arranged by masking Object 2 . Therefore, the principal prediction was that an unmasked (more visible) object would decrease the visibility of a simultaneous, masked (less visible), identical distant object (Experiments 1-2). The two objects were also placed quite close to each other, so that they would be apprehended as only one group, to determine whether the DV of Experiments 1-2 would disappear and perhaps be replaced by an IV (Experiment 3). Finally, the mask was eliminated to determine whether the DV would again disappear (Experiment 4).

\section{EXPERIMENT 1}

An object that is hardly visible should be difficult to discriminate from its absence (background). Therefore, according to the principal prediction (above), an unmasked (more visible) object should make it relatively difficult to discriminate a simultaneous, masked (less visible), identical distant object from its absence; this discrimination should be more difficult than when the unmasked object does not occur. A corollary prediction is that the unmasked object should produce relatively frequent misses of the masked object.

\section{Method}

Stimuli. There were 2 (unmasked object: present or absent) $\times 2$ (masked object: present or absent) $=4$ stimuli. Figure 1 indicates that the unmasked object was a horizontal line in a high vertical (top) location, and the masked object was an identical horizontal line in a low vertical (bottom) location directly below it. These bottom-line (A), no-lines (B), top-plus-bottom-lines (C), and top-line (D) stimuli were all accompanied by the mask, which consisted of two somewhat wider and more intense horizontal lines that flanked the location of the bottom line to the left and right. The top and bottom lines began and terminated together prior to the flanking lines, which were also simultaneous. The interstimulus interval was $0 \mathrm{msec}$. The same timing occurred when the top and/or bottom lines did not occur. Information about stimulus duration appears below. The experiment was accomplished with MEL (Psychology Software Tools, Inc.) on an IBM-compatible personal computer with EGA graphics.

The distance between the top and bottom lines was $13 \mathrm{~mm}$ $\left(1.7^{\circ}\right)$. The bottom line was at the center of the monitor. The length of all lines was $8 \mathrm{~mm}$. The width of the top and bottom lines was about $0.3 \mathrm{~mm}$, and the width of the flanking lines was about $0.6 \mathrm{~mm}$. The luminances of these two pairs of lines were $10 \mathrm{~cd} / \mathrm{m}^{2}$ and $110 \mathrm{~cd} / \mathrm{m}^{2}$, respectively. The luminance of the background was $0.1 \mathrm{~cd} / \mathrm{m}^{2}$.

Subjects and Procedures. The subjects were 16 students from the introductory course in psychology at Howard University. They received course credit for participation.

Half the subjects discriminated the top-line-absent stimuli (A and $B$ ) in an initial stage and the top-line-present stimuli ( $C$ and D) in a subsequent stage. The remaining half received the stages in the reverse order. Prior to each of these discriminations between bottom-line-present and bottom-line-absent stimuli, the experimenter provided a "choice" sheet with drawings of the two stimuli to be discriminated. These drawings approximated those in Figure 1. However, they had the length and spatial separation of the actual experimental stimuli. In addition, a "1" occurred beneath each bottom-line-present drawing, and a " 2 " occurred beneath each bottom-line-absent drawing. Subjects were told to decide which of the two stimuli occurred on each trial. They indicated their decisions by pressing the " 1 " and " 2 " keys on the computer keyboard.

For each trial, a 1,000-msec warning stimulus (a $4 \times 4 \mathrm{~mm}$ red cross at the center of the monitor), a 1,000-msec dark period, an experimental stimulus (A, B, C, or D), and the subject's choice (response) occurred in that order. For each discrimination (stage), there were 10 preliminary "practice" trials. For these trials, the duration of the top and bottom lines and also of the flanking lines was $1,000 \mathrm{msec}$. In addition, if the subject made more than one error, he/she was corrected. Then the experimenter told the subject that the succeeding stimuli would occur more quickly and that the task would be more difficult. For these 20 test trials, the duration of the top and bottom lines and also of the flanking lines was $17 \mathrm{msec}$. For both the practice and the test trials, each of the two stimuli occurred randomly with equal probability.

\section{Results}

Informal observations suggest that the top line decreases the visibility of the bottom line. (These observations and also observations with the top and bottom lines close together were previously indicated, but there was no accompanying experimental evidence [King, 1993].) According to these observations, the bottom line is missed (invisible) more frequently when the top line is present than when it is absent. Likewise, when the bottom line is faintly visible-for example, because only one flanking line is used-it is dimmer when the top line

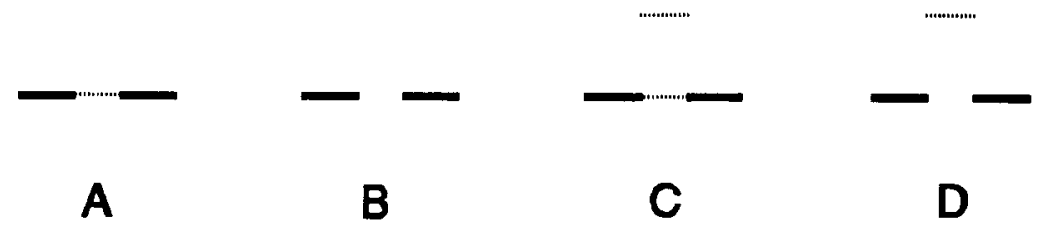

Figure 1. Illustrations of the four (A, B, C, and D) stimuli for Experiment 1. See text for further information. 


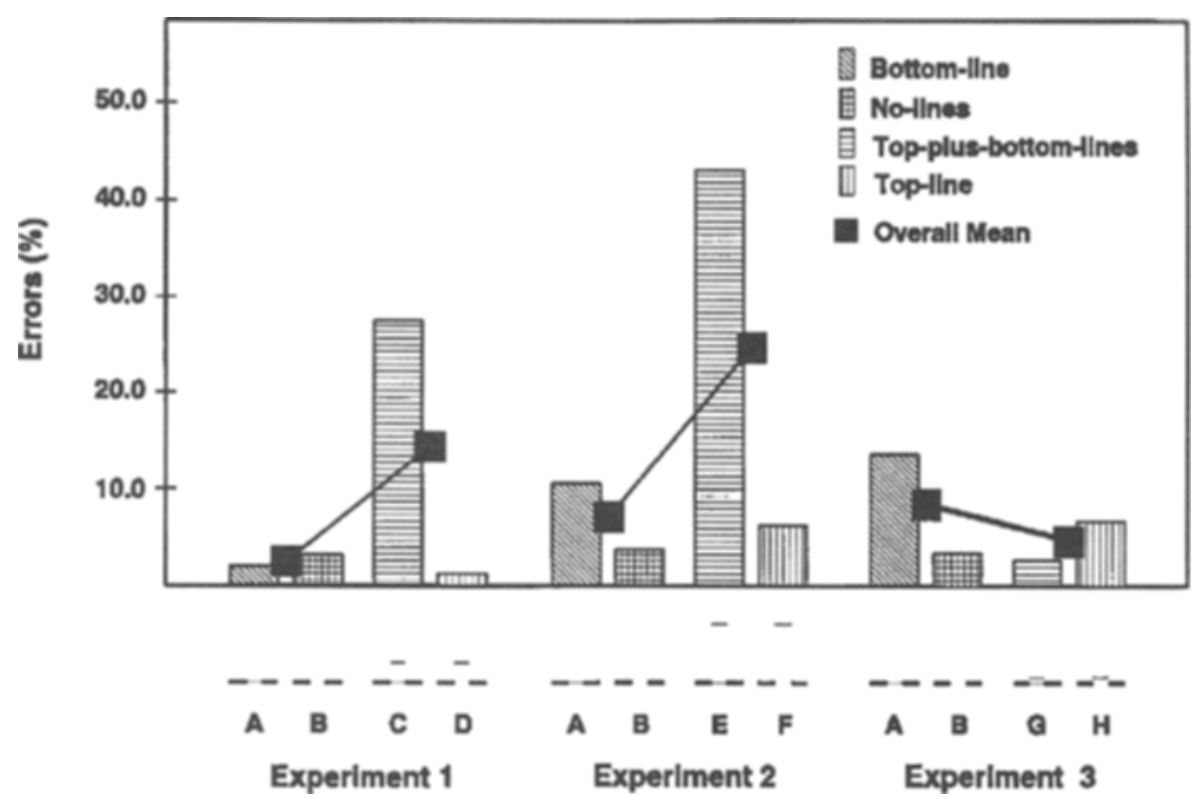

Figure 2. Experiments 1-3: In each experiment, the presence of the bottom line was discriminated from its absence under two conditions, with the top line absent and the top line present. The top-line-absent stimuli were always $A$ and $B$. In contrast, the top-line-present stimuli had lines that were distant, very distant, or close (stimuli C-D, E-F, and G-H for Experiments 1-3, respectively). Each column indicates the mean percentage of errors to the stimulus depicted below it. Each square indicates the overall mean percentage of errors on a discrimination (it is the average of the percentages indicated by the two adjacent columns). These squares imply that the distant and very distant top lines interfered with the presenceversus-absence discrimination of the bottom line, whereas the near top line improved this discrimination. The two very high columns indicate that both the distant and the very distant top lines frequently resulted in misses of the bottom line, implying that the interference was due to a decrease in visibility.

is present than when it is absent. In addition, the bottom line seems to retain its own identity, rather than to perceptually integrate (fuse) with the flanking lines.

The discrimination results are consistent with these observations. To show this, false identifications of each stimulus as the other same-stage (hence same-discrimination) stimulus were summed across the 20 test trials of each stage and averaged. These averages were the entries for an $\times$ order (top-line-present stimuli first, top-line-absent stimuli first) factorial analysis of variance (ANOVA). The order factor was between subjects. The ensuing means of errors for each stimulus, expressed as percentages, are indicated in Figure 2. The means of the two means for each discrimination - that is, the overall top-line-present and top-line-absent means-are also indicated.

The top-line-present ( $\mathrm{C}$ vs. D) discrimination produced a greater overall mean percentage of errors than did the top-line-absent (A vs. B) discrimination $[F(1,14)=$ $11.33, p<.01]$. This main effect of the top line occurred because the top-plus-bottom-lines stimulus (C) produced more errors than did any of the three remaining stimuli $[F(1,14)=30.91,28.08$, and $32.38, p s<.001$, for the $\mathrm{C}-\mathrm{A}, \mathrm{C}-\mathrm{B}$, and $\mathrm{C}-\mathrm{D}$ comparisons, respectively]. Accordingly, the top line $\times$ bottom line interaction was also significant $[F(1,14)=17.84, p<.001]$.

The top-line-present and top-line-absent discriminations occurred in different stages. Therefore, subjects may have employed different decision criteria for these stages. Consequently, a signal detection analysis was made. Performance on a stimulus was sometimes either perfect or always incorrect. Information about the noise and signal-plus-noise distributions was lacking. Consequently, $A^{\prime}$, a nonparametric analog of $d^{\prime}$ (Gescheider, 1985; Grier, 1971; I. Pollack \& Norman, 1964; Snodgrass, Levy-Berger, \& Haydon, 1985) was obtained for each subject by combining the proportion of correct identifications of bottom-line-present stimuli (hits) with the proportion of false identifications of bottom-lineabsent stimuli as bottom-line-present stimuli (false alarms). The ensuing top line (present, absent) $\times$ order (top-line-present stimuli first, top-line-absent stimuli first) ANOVA indicated that the top-line-present discrimination resulted in a mean $A^{\prime}$ of .923 , and the top-line-absent discrimination resulted in a mean $A^{\prime}$ of $.984[F(1,14)=10.00, p<.01]$.

\section{Discussion}

The bottom line was discriminated from its absence. The top-line-present stimuli produced more errors and a lower $A^{\prime}$ on this detection task than did the top-lineabsent stimuli. This was because the top-plus-bottomlines stimulus was frequently falsely identified as the top-line stimulus. These false identifications are misses of the bottom line, implying that it was frequently invis- 
ible. The conclusion: the top line decreased the visibility of the bottom line (a DV).

The unmasked top line was more visible than the masked bottom line. The two lines were distant and hence readily apprehended as separate groups. Therefore, the DV indicates that the more visible line (group) decreased the visibility of the less visible line (group). Consequently, this DV is consistent with the introduction's evidence that a more visible (more intense, larger, present) object (group) decreases the visibility of a less visible (less intense, smaller, terminated) object (group). Likewise, the DV supports the relative-visibility position.

The DV means that the top line reduced the similarity between its visibility and the bottom line's visibility. That is, the top line produced contrast, but for visibility, rather than for a typical attribute (e.g., color). Contrast does not occur between perceptually equal attributes. Therefore, this nonoccurrence may be the reason why two simultaneous equally visible (e.g., identical) distant objects do not result in a DV, which implies that contrast governs DVs-the DV-as-contrast theory. Further, recall that this theory is consistent with evidence that two groups, contrast, and DVs are associated - that is, the 2groups-contrast-DV position.

Moreover, the present DV is not accounted for by other extant phenomena and theories. Metacontrast and paracontrast were not involved, because the top and bottom lines were simultaneous. This simultaneity also means that top-line-produced transient (hence, fastlatency) activity in one channel preceded bottom-lineproduced sustained (thus, slow-latency) activity in a second channel. Therefore, the latter activity should not have been inhibited, indicating that the present DV is not attributable to the transient-against-sustained inhibition of Breitmeyer and Ganz (1976).

The durations of the top and bottom lines were equal and very brief. Therefore, the neural fatigue for the top and bottom lines should have been equal, if there was any fatigue at all. Consequently, the neural fatigue explanation of the decrease in visibility that occurs in selective adaptation (Blakemore \& Campbell, 1969) does not apply either.

The locations of the top and bottom lines were fixed, as the practice trials indicated from the start. Therefore, the attentional type of interference that is eliminated by precuing the location of the target (Kahneman, Treisman, \& Burkell, 1983) was not operative.

A DV does not occur with two simultaneous, equally visible distant objects, including according to the 1 versus 2 task, in which both objects are logically relevant. Thus, even a logically relevant object does not elicit (command) attention away from a simultaneous spatially separated object. Moreover, the top line was logically irrelevant. Therefore, it should not have elicited attention away from the bottom line.

Perhaps the four lines of the top-plus-bottom-lines stimulus overwhelmed limited capacity or resources. But this possibility does not explain the ability of more intense, larger, and present (rather than terminated) objects to produce DVs. It is not parsimonious.

The top and bottom lines were identical. Therefore, a Stroop-like interference between opposing attributes, such as opposing orientations (Palmer \& Bucher, 1981), was not operative.

The concept of preattentive processing (Beck, 1982; Julesz, 1984; Marr, 1982; Treisman \& Gelade, 1980) is also questioned. According to this concept, there is an early parallel identification of "discontinuities between more homogeneous areas," the registration of "the true structure of the scene," and the "separating of real objects from their backgrounds" (i.e., the segregation of "figure from ground") (Treisman, 1986, pp. 35-50). The present top and bottom lines were simultaneous discontinuities that were separated by a fairly large distance, hence a fairly large homogeneous dark background. Therefore, the concept of preattentive processing incorrectly implies that the perception of the bottom line will be "true," hence that a DV of the bottom line will not occur. Consequently, this DV would have to be attributed to a later stage of processing, despite the use of a detection (not identification) task and a brief stimulus duration.

\section{EXPERIMENT 2}

Experiment 2 tested the prediction that the DV of the bottom line would attenuate when the distance between the top and bottom lines was three times as great as in Experiment 1. This prediction followed from evidence that an increase in the distance between a target object/ feature and a context (logically irrelevant) object/ feature improves performance for metacontrast (Alpern, 1953; Growney et al., 1977; Kolers \& Rosner, 1960), identification (Strasburger, Harvey, \& Rentschler, 1991, brief review), and classification (Garner \& Felfoldy, 1970). Such an improvement is also predicted by lateral inhibition. Nevertheless, the tripling in distance between the top and bottom lines still resulted in the apprehension of each line as its own group (two in all), implying that the prediction would be disconfirmed.

\section{Method}

Experiment 2 was identical to Experiment 1, except that the top line was replaced with one that was three times as far away from the bottom line, and there were new subjects. Figure 2 depicts the new (E and F) and also the unchanged (A and B) stimuli.

\section{Results}

The results were analyzed as in Experiment 1. Figure 2 indicates that the top-line-present $(\mathrm{E}-\mathrm{F})$ discrimination produced a greater overall mean percentage of errors than did the top-line-absent $(\mathrm{A}-\mathrm{B})$ discrimination $[F(1,14)=18.33, p<.001]$. Accordingly, the top-linepresent discrimination resulted in a mean $A^{\prime}$ of .822, and the top-line-absent discrimination resulted in a mean $A^{\prime}$ of $.960[F(1,14)=10.07, p<.01]$. The top-line-present discrimination produced these error and signal detec- 
tion outcomes because the top-plus-bottom-lines stimulus (E) produced frequent misses: they were more frequent than the errors produced by the three remaining stimuli $[F(1,14)=29.62,43.53$, and $35.18, p \mathrm{~s}<.001$, for the E-A, E-B, and E-F comparisons, respectively]. Thus, the top line $\times$ bottom line interaction was significant $[F(1,14)=12.62, p<.01]$. All these results approximate those of Experiment 1.

\section{Discussion}

The top line decreased the visibility of the simultaneous identical bottom line even slightly more than in Experiment 1 , despite the $5.2^{\circ}$ distance between these two lines. Clearly, the metacontrast, crowding, classification, and lateral inhibition types of interference mentioned in the introduction to this experiment could not have been responsible for this DV. This $5.2^{\circ}$ distance still results in the apprehension of each line as its own group (two in all). Therefore, the results are consistent with the 2 groups-contrast-DV position and the related DV-ascontrast theory.

\section{EXPERIMENT 3}

A top line decreased the visibility of an identical distant or very distant bottom line (Experiments 1-2). So, two groups were associated with a DV of the less visible group. But one group may be associated with an opposing IV (see the present introduction). Therefore, altering the top and bottom lines so that they would be more readily apprehended as one group should eliminate the DV and perhaps result in an IV. This prediction was tested by placing the top line close to the bottom line. With this placement, the top and bottom lines are apprehended as one group to a greater extent than when they are more distant, in accord with the gestalt principle of proximity.

\section{Method}

The top line of Stimuli C and D was replaced with one that was three times as close to the bottom line. Figure 2 depicts these new stimuli ( $\mathrm{G}$ and $\mathrm{H}$ ) and also the unchanged stimuli ( $A$ and $B)$. In addition, there were 15 subjects (all new). Otherwise, the method was identical to that of Experiment 1.

\section{Results}

Informal observations suggest that the bottom line is more visible when the top line is present than when it is not, the reverse of what was found previously. In addition, the top and bottom lines seem to retain their individual identities: they do not appear to perceptually integrate (fuse) either with each other or with the flanking lines. Thus, the top and bottom lines produce the impression of an unfilled horizontal row or bar (one group).

The results were analyzed as in Experiment 1. Consistent with the informal observations and in opposition to the highly significant results of Experiments 1-2, Figure 2 reveals that the top-line-present ( $G$ vs. $H$ ) discrimination produced a lower (not higher) overall mean per- centage of errors than did the top-line-absent (A vs. B) discrimination $[F(1,28)=4.28, p<.05]$. The topline-present $A^{\prime}$ mean (.975) and the top-line-absent $A^{\prime}$ mean $(.955)$ were also reversed $[F(1,28)=3.00, p<$ $.10]$. Moreover, the top-plus-bottom-lines stimulus $(\mathrm{G})$ produced the least (not most) errors of any stimulus $[F(1,28)=16.16,0.06$, and $2.14, p \mathrm{~s}<.001$, n.s., and n.s. for the $\mathrm{G}-\mathrm{A}, \mathrm{G}-\mathrm{B}$, and $\mathrm{G}-\mathrm{H}$ comparisons, respectively]. Accordingly, the top line $\times$ bottom line interaction was significant $[F(1,28)=13.72, p<.001]$.

Figure 2 also reveals that in Experiment 1 the bottomline stimulus (A) resulted in less errors than did the nolines stimulus (B), whereas the reverse occurred in Experiment 2, and also in Experiment 3, even though the stimuli were identical. Therefore, the $A^{\prime}$ scores for stimuli A and B of all three experiments were analyzed together, making the ANOVA a 3 (Experiment: $1-3$ ) $\times 2$ (order: top-line-present stimuli first, top-line-absent stimuli first) factorial in which both factors were between subjects. The main effect of experiment was not significant $[F(2,56)=1.67, p>.10]$. Consequently, this error reversal could have stemmed from between-subjects variability.

\section{Discussion}

Placing the top line close to the bottom line eliminated the DV of the bottom line. In fact, there were hints of an opposing IV: (1) The top-line-present discrimination produced significantly less overall errors and a nearly significantly greater $A^{\prime}$ than did the top-line-absent discrimination. (2) The top-plus-bottom-lines stimulus produced the least errors, including significantly fewer errors than did the bottom-line stimulus. The present top and bottom lines were near and hence were apprehended as a stronger single group (or as weaker separate groups) than were the previous more distant top and bottom lines. Therefore, these hints are consistent with the introduction's evidence that one group is associated with an IV.

These hints are also consistent with an $I V-a s$ assimilation theory that corresponds to the DV-ascontrast theory. This is because an IV of the bottom line would mean that the similarity between its visibility and that of the top line had increased. In other words, assimilation is implied, but for visibility, rather than for a traditional attribute. Moreover, IV-as-assimilation theory is consistent with the lgroup-assimilation-IV position, just as DV-as-contrast theory is consistent with the 2groupscontrast-DV position. Whether an IV occurs between objects that are equally visible, and whether IV-asassimilation theory is consistent with previous evidence of an IV (King et al., 1993; King \& Thomas, 1993) will not be considered at this point.

Metacontrast, crowding, lateral inhibition, and classification interference should increase with a decrease in context-target proximity (introduction to Experiment 2 ). Moreover, neither these types of interference, nor the transient-against-sustained (Breitmeyer \& Ganz, 1976), neural fatigue (Blakemore \& Campbell, 1969), attentional 
(Kahneman et al., 1983), elicitation (command) of attention, competition for capacity/resources, and Stroop-like types of interference (Experiment 1) account for the ability of the near top line to reverse the results of Experiments $1-2$.

\section{EXPERIMENT 4}

A DV does not occur with two simultaneous equally visible distant objects, which is consistent with DV-ascontrast theory. Therefore, the top line should no longer decrease the visibility of the bottom line when these two lines are equally visible. This was arranged by removing the bottom line's mask (i.e., the flanking lines). Because the bottom line is thereby obviously visible, a speeded response task was used. The one employed was the one versus two task, because this type of task is sensitive to a DV (King, 1990b).

\section{Method}

The method was as in Experiment 1, except as follows. The two stimuli were Experiment 1's top-plus-bottom-lines and bottomline stimuli, but without the flanking lines. They are depicted in Figure 3 . The instructions to 10 new subjects were to press the "F" key with the left hand if one line occurred and to press the " $\mathrm{K}$ " key with the right hand if two lines occurred. This was to be done as quickly as possible without making errors. Another 10 subjects had the reverse hand assignments. There was one block of 64 trials.

\section{Results}

Both average response times (RTs) and errors to each stimulus were obtained by summing across Trials 17-64. The two ANOVAs were stimulus (top-plus-bottom-lines, bottom-line) $\times$ hand (left, right) factorials, with the second factor between subjects. Figure 3 indicates the ensuing mean RTs and errors for the two stimuli. The top-plus-bottom-lines stimulus produced a nearly significantly faster RT than did the bottom-line stimulus $[F(1,18)=3.50, p<.10]$. In addition, these two stimuli produced the same percentage of errors.

\section{Discussion}

If the visibility of the bottom (and/or top) line of the top-plus-bottom-lines stimulus had decreased, then this stimulus should have produced the slower RT. Yet the reverse result occurred to an extent that approached significance. Therefore, a DV did not occur, as is consistent with previous empirical evidence and the DV-as-contrast theory.

This absence of a DV also questions alternative theories of DVs. For example, in Experiments 1-2 the top line should not have produced metacontrast, induced crowding, caused lateral inhibition, or elicited attention, because it should have also produced these interferences in the present experiment.

\section{GENERAL DISCUSSION}

To summarize, an unmasked (more visible) top line decreased the visibility of a simultaneous, masked (less

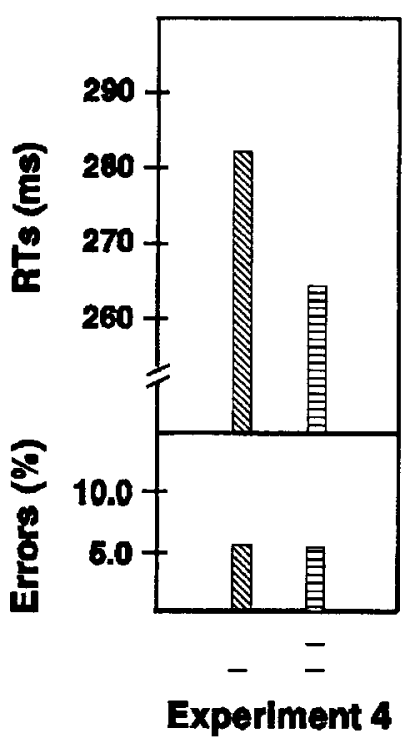

Figure 3. Experiment 4: The top-plus-bottom-lines stimulus was discriminated from the bottom-line stimulus. The columns indicate the mean response time or mean percentage of errors to each of these stimuli. Performance was almost significantly better on the top-plus-bottom-lines stimulus than on the bottom-line stimulus.

visible), identical distant bottom line. This decrease supports the relative-visibility position, but it is unexplained by numerous extant phenomena and theories. Moreover, DV-as-contrast theory explains this and other relativevisibility DVs, accounts for the nonoccurrence of DVs when two equally visible objects are apprehended as separate groups, is consistent with the 2groups-contrast-DV position, and hence is also consistent with both the corresponding 1 group-assimilation-IV position and the hint of an opposing IV that occurred when the top and bottom lines were close.

Of course, the present effects of distance may have been due to distance (proximity) per se, rather than to its association with grouping. But when proximity and grouping were unconfounded, the two objects that were less proximal but produced the stronger group were more difficult to discriminate between (King, 1990a; King \& Thomas, 1993). Moreover, a high similarity did not substitute for a low proximity, because the two stronggroup objects were less similar to each other than were the two weak-group objects. Therefore, grouping predicted performance, whereas the prediction by physical factors was at best ambiguous. Nor did this performance stem from a local effect of the lines that were added to the strong-group objects to produce the weak-group objects.

There is additional evidence that a high proximity improves performance. Recall that making two rectangles contiguous eliminated evidence of a large-against-small DV (King, 1990b). In addition, superimposition of a target and context produced less attentional interference than did their spatial separation (Treisman, Kahneman, \& Burkell, 1983). Also, locating color and shape targets in 
the same object, rather than in spatially separated objects, either reduced or eliminated the divided attention type of interference (Pollatsek \& Digman, 1977).

The hint of an IV when the top and bottom lines were close is also consistent with closure. If nearby lines can increase false identifications of an empty space as essentially identical to these lines (closure, but also akin to false alarms), then a nearby line should also reduce misses of an actually present identical line. Accordingly, in Experiment 3, the top line resulted in more frequent false alarms of the bottom line than misses of the bottom line, even though when the top line was absent, the frequencies of these two types of errors were reversed. Another point: Because closure can also be regarded as assimilation (see the introduction), a connection between context-produced effects on visibility and perceived similarity is again implied.

Metacontrast is consistent with the relative-visibility position and hence with the DV-as-contrast theory. Nevertheless, the effects of the target-to-mask distance in metacontrast and the top-to-bottom distance in the present research differ. To address this difference, assume that if the component stimuli producing one group become sufficiently dissimilar in time of occurrence, spatial location, and/or other attributes from those producing a second group, then these two groups interact less (move toward independence) and concomitantly contrast and DVs attenuate (cf. King, 1988a). For metacontrast, the temporal dissimilarity between the target and mask may be sufficient to make these objects function as two separate but interacting groups. If so, an increase in the distance between these objects should move the groups that they produce toward independence, which explains why this increase attenuates metacontrast (Alpern, 1953; Growney et al., 1977; Kolers \& Rosner, 1960). The close top and bottom lines are highly similar in time of occurrence and in attributes, as well as in proximity, in accord with their apprehension as one group. Therefore, even a very large distance between the top and bottom lines may be insufficient to move the two groups that they produce toward independence, which explains why this distance did not attenuate the DV. If so, some further dissimilarity in proximity, time, and so forth between the top and bottom lines may be needed to approach independence and hence reduce the DV.

\section{REFERENCES}

ALPERN, M. (1953). Metacontrast. Journal of the Optical Society of America, 43, 648-657.

BECK, J. (1966). Contrast and assimilation in lightness judgments. Perception \& Psychophysics, 1, 342-344.

BECK, J. (1982). Textural segmentation. In J. Beck (Ed.), Organization and representation in perception (pp. 285-317). Hillsdale, NJ: Erlbaum.

BEVAN, W., \& GAYLORD, S. (1978). Stimuli, the perceiver, and perception. In R. D. Walk \& H. L. Pick, Jr. (Eds.), Perception and experience (pp. 361-385). New York: Plenum.

Blakemore, C., \& CAMpbell, F. W. (1969). On the existence of neurons in the human visual system selectively sensitive to the orientation and size of retinal images. Journal of Physiology, 203, 237-260.

BREITMEYER, B. G., \& GANZ, L. (1976). Implications of sustained and transient channels for theories of visual pattern masking, saccadic suppression, and information processing. Psychological Review, 83, 1-36.

Brigell, M., \& UhlariK, J. (1979). The relational determination of length illusions and length aftereffects. Perception, 8, 187-197.

Coren, S., \& Girgus, J. S. (1978). Seeing is deceiving: The psychology of visual illusions. Hillsdale, $\mathrm{NJ}$ : Erlbaum.

COREN, S., \& Girgus, J. S. (1980). Principles of perceptual organization and spatial distortion: The gestalt illusions. Journal of Experimental Psychology: Human Perception \& Performance, 6, 404-412.

DAY, R. H., \& JORY, M. K. (1980). A note on a second stage in the formation of illusory contours. Perception \& Psychophysics, 27, 89-91.

FeHRER, E., \& SMITH, E. (1962). Effect of luminance ratio on masking. Perceptual \& Motor Skills, 14, 243-253.

Fuchs, W. (1967a). Completion phenomena in hemianopic vision. In W. D. Ellis (Ed. and Trans.), A source book of Gestalt psychology (pp. 344-356). New York: Humanities Press. (Original paper published 1921)

Fuchs, W. (1967b). The influence of form on the assimilation of colours. In W. D. Ellis (Ed. and Trans.), A source book of Gestalt psychology (pp. 95-103). New York: Humanities Press. (Original paper published 1923)

GARNER, W. R., \& FELFOLDY, G. L. (1970). Integrality of stimulus dimensions in various types of information processing. Cognitive Psychology, 1, 225-241.

GAYLORD, S. (1984). Effects of inter-stimulus distances on the formation of category boundaries. Unpublished doctoral dissertation, Duke University, Durham, NC.

Gescheider, G. A. (1985). Psychophysics: Method, theory, and application (2nd ed.). Hillsdale, NJ: Erlbaum.

GRIER, J. B. (1971). Nonparametric indexes for sensitivity and bias: Computing formulas. Psychological Bulletin, 75, 424-429.

Growney, R., Weisstein, N., \& Cox, S. I. (1977). Metacontrast as a function of spatial separation with narrow line targets and masks. Vision Research, 17, 1205-1210.

Hartmann, G. W. (1935). Gestalt psychology. New York: Ronald Press. Helson, H., \& JoY, V. L. (1962). Domains of lightness assimilation and contrast. Psychologische Beiträge, 62, 405-415.

JoRdan, K., \& SChiano, D. J. (1986). Serial processing and the parallel-lines illusion: Length contrast through relative spatial separation of contours. Perception \& Psychophysics, 40, 384-390.

JORDAN, K., \& UHLARIK, J. (1985). Assimilation and contrast of perceived length depend on temporal factors. Perception \& Psychophysics, 37, 447-454.

JULESZ, B. (1984). Toward an axiomatic theory of preattentive vision. In G. Edleman, W. Einer, \& W. Cowan (Eds.), Dynamic aspects of neocortical function (pp. 585-612). New York: Wiley.

Kahneman, D., Treisman, A., \& Burkell, J. (1983). The cost of visual filtering. Journal of Experimental Psychology: Human Perception \& Performance, 9, 510-522.

Kanizsa, G. (1988). Colour and organization: A response to King. New Ideas in Psychology, 6, 289-291.

KING, D. L. (1988a). Assimilation is due to one perceived whole and contrast is due to two perceived wholes. New Ideas in Psychology, 6, 277-288.

KING, D. L. (1988b). Strong phenomenal wholes are associated with fast "same" and slow "different" responses and superior overall performance. Perception \& Psychophysics, 43, 485-493.

KING, D. L. (1990a). Gestalts are more closely associated with performance on a discrimination task than are component stimuli. American Journal of Psychology, 103, 37-52.

KING, D. L. (1990b). A large rectangle delays the perception of a separate small rectangle. Perception \& Psychophysics, 47, 369-378.

KING, D. L. (1993). A dominant-subordinate unit-against-unit theory of decreases in visibility. Perceptual \& Motor Skills, 76, 667-673.

KING, D. L., Hicks, H., \& BRown, P. D. (1993). Context-produced increases in visibility. Psychological Research, 55, 10-14.

King, D. L., Phillips, W., \& Mose, J. F. (in press). Association of assimilation and an increase in visibility in perceptual grouping. $P s y$ chological Research.

KING, D. L., \& THOMAS, J. (1993). Two effects of context on the presence/ absence of connecting segments. Perception \& Psychophysics, 53, 489-497. 
KOFFKA, K. (1935). Principles of Gestalt psychology. New York: Harcourt, Brace, \& World.

Kolers, P. A., \& RosNer, B. S. (1960). On visual masking (metacontrast): Dichoptic observation. American Journal of Psychology, 77, $2-21$.

LoCKHEAD, G. R. (1988). Assimilation and contrast: Two processes or one? A response to King. New ldeas in Psychology, 6, 293-299.

Marr, D. (1982). Vision. San Francisco: W. H. Freeman.

MuSATti, C. (1931). Forma e assimilazione [Form and assimilation]. Archivio Italiano di Psicologia, 9, 213-269.

OBONAI, T. (1954). Induction effects on estimates of extent. Journal of Experimental Psychology, 47, 57-60.

Palmer, S. E., \& Bucher, N. M. (1981). Configural effects in perceived pointing of ambiguous triangles. Journal of Experimental Psychology: Human Perception \& Performance, 7, 88-114.

POLlaCk, I., \& NoRman, D. A. (1964). A non-parametric analysis of recognition experiments. Psychonomic Science, 1, 125-126.

POLLACK, R. H. (1964). Simultaneous and successive presentation of elements of the Mueller-Lyer figure and chronological age. Perceptual \& Motor Skills, 19, 303-310.

Pollatsek, A., \& Digman, L. (1977). Dependent spatial channels in visual processing. Cognitive Psychology, 9, 326-352.

Prinzmetal, W. (1981). Principles of feature integration in visual perception. Perception \& Psychophysics, 30, 330-340.

Prinzmetal, W., \& Keysar, B. (1989). Functional theory of illusory conjunctions and neon colors. Journal of Experimental Psychology: General, 118, 165-190.

Pulos, E., Raymond, J. D., \& Makous, W. (1980). Transient sensitization by a contrast flash. Vision Research, 20, 281-288.
Ramachandran, V. S. (1992, May). Blind spots. Scientific American, 266, 86-91.

Sagara, M., \& Oyama, T. (1957). Experimental studies on figural aftereffects in Japan. Psychological Bulletin, 54, 327-338.

SCHiller, P. H., \& Sмiтh, M. C. (1966). Detection in metacontrast. Journal of Experimental Psychology, 71, 32-39.

Snodgrass, J. G., LeVy-Berger, G., \& Haydon, M. (1985). Human experimental psychology. New York: Oxford University Press.

Strasburger, H., Harvey, L. O., JR., \& Rentschler, I. (1991). Contrast thresholds for identification of numeric characters in direct and eccentric view. Perception \& Psychophysics, 49, 495-508.

Treisman, A. (1986). Properties, parts, and objects. In K. R. Boff, L. Kaufman, \& J. P. Thomas (Eds.), Handbook of perception and human performance: Vol. 2. Cognitive processes and performance (pp. 35-1 to 35-70). New York: Wiley.

Treisman, A., \& Gelade, G. A. (1980). A feature integration theory of attention. Cognitive Psychology, 12, 97-136.

Treisman, A., Kahneman, D., \& Burkell, J. (1983). Perceptual objects and the cost of filtering. Perception \& Psychophysics, 33, 527-532.

vaN Tuvu, H. F. J. M. (1975). A new visual illusion: Neonlike color spreading and complementary color induction between subjective contours. Acta Psychologica, 39, 441-445.

WARE, C. (1980). Colored illusory triangles due to assimilation. Perception, 9, 103-107.

WeISSteIN, N., \& HarRis, C. S. (1974). Visual detection of line segments: An object-superiority effect. Science, 186, 752-756.

(Manuscript received September 30, 1993; revision accepted for publication September 18, 1994.) 